\title{
Quantitative Analysis of Multi-components in Curcuma xanthorrhiza by Single Marker
}

\author{
Badrunanto1, Wulan Tri Wahyuni, ${ }^{1,2}$ and Mohamad Rafi, ${ }^{1,2 *}$
}

1. Department of Chemistry, Faculty of Mathematics and Natural Sciences, IPB University, Jl. Raya Dramaga, Bogor 16880, West Java, Indonesia.

2. Tropical Biopharmaca Research Center, Institute of Research and Community Services, IPB University, Jl. Taman Kencana No. 3, Bogor 16128, West Java, Indonesia.

\begin{abstract}
Info Article
Submitted: $05-07-2019$

Revised: 23-10-2019

Accepted: 27-11-2019

*Corresponding author

Mohamad Rafi

Email:

mra@apps.ipb.ac.id

ABSTRACT

A new simple and effective routine analytical method for quantification of curcuminoids in Curcuma xanthorrhiza was developed by highperformance liquid chromatography. This method based on chromatographic fingerprint combined with a quantitative analysis of multi-components by single marker (QAMS). Curcumin was selected as an internal marker for the determination of two other similar compounds, i.e. bisdemethoxycurcumin and demethoxycurcumin, by using the relative coefficient factor (RCF). Excellent linearity was obtained for each component $\left(r^{2}>0.9998\right)$, and the recovery of extraction methods were within 100.23-103.95\%. The precision of the method was good at inter-day and intra-day analysis (RSD $<4.0 \%)$. The stability of RCFs was good under various chromatographic conditions with RSD $<1 \%$, and the ratio of retention time was used to locate each compound. The quantification of curcuminoids between QAMS and external standard method (ESM) proved the consistency and similarity of the two method (RSD $<2 \%$ ). This study demonstrated that QAMS could be used as a routine method for quality control of curcuminoids in $C$. xanthorrhiza. This method successfully proved accurate, stable, more effective and simple than external standard method.
\end{abstract}

Keywords: C. xanthorrhiza, curcuminoids, QAMS, relative coefficient factor

\section{INTRODUCTION}

Curcuma xanthorrhiza belongs to the Zingiberaceae family and locally known as temulawak. This plant is origin and widely distributed in Indonesia. The dried rhizome of $C$. xanthorrhiza has been used for a long time as traditional medicine by Indonesian people, called jamu. Many pharmacological studies showed the efficacy of $C$. xanthorrhiza, such as antiinflammatory and antihyperglicemic (Kim et al. 2014), antimicrobial (Mangunwardoyo et al. 2012), antioxidant and hepatoprotective activity (Devaraj et al. 2010). The pharmacological properties of $C$. xanthorrhiza are related to their chemical content, including curcuminoids. In the previous study, curcumin (CUR), bisdemethoxycurcumin (BDMC), and demethoxycurcumin (DMC) were found in $C$. xanthorrhiza with CUR content is higher than BDMC and DMC (Rafi et al. 2015). Curcuminoids are known for their pharmacological properties, i.e., antioxidant, antifungal, antiviral, anti-inflammatory, and anticancer (Fadus et al. 2017; Kocaadam and Şanlier 2015; Moghadamtousi et al. 2014). Curcumin has higher pharmacological activity than bisde methoxycurcumin and demethoxycurcumin (Sandur et al. 2007; Jayaprakasha et al. 2006). However, the mixture of three curcuminoids has better activity compared only curcumin (Rege et al. 2014).

Evaluation of medicinal plant raw material commonly used a marker compound like curcuminoids in $C$. xanthorrhiza. The most analytical technique used for quantitative analysis of curcuminoids in Curcuma genus are liquid chromatography as reported by Osorio-Tobón et al. (2016), Erpina et al. (2017), Chao et al. (2018), and Poudel et al. (2019). However, with those method we must use the three curcuminoid standard with high purity which is expensive and not easy to get. So, we need a new method which is more efficient, precise, accurate, and inexpensive to determine curcuminoids for quality evaluation of $C$. 
xanthorrhiza raw material. Wang et al. (2006) systematically proposed a quantitative analysis of multicomponent by single marker (QAMS). This method, based on the principle of the absorption (A), is linearly proportional to the concentration (W) of an analyte within a concentration range (W = f.A). It only uses one component to determine other components and use their internal relationship and proportion (Zhu et al. 2017). In recent years, this method has been widely used as an alternative method for quality control of many medicinal plants (Li et al. 2017; Peng et al. 2018; Wang et al. 2016; Xu et al. 2017). QAMS has been used for the determination of curcuminoids in C. longa (Chen et al. 2017). However, there is no paper has been reported regarding the use of QAMS in determination of curcuminoids in C. xanthorriza. Also, the mobile phase for the separation of curcuminoids in C. longa by HPLC was separated in low $\mathrm{pH}$, and this is not safe for the durability of the stationary phase in the column. In this study, we proposed a new method using QAMS for quality control of $C$. xanthorrhiza based on the determination of curcuminoids content by only use curcumin as a single marker. By using only one component to determine other curcuminoids, it will increase the effectiveness, efficiency, and cost of analysis without sacrificing the quality of the analytical result.

\section{MATERIAL AND METHODS \\ Chemicals and materials}

Bisdemethoxycurcumin, demethoxycurcumin, and curcumin with the purity $>95 \%$ were purchased from ChromaDex Inc. (Santa Ana, CA, USA). Methanol, acetonitrile, formic acid of HPLC grade were obtained from Merck (Darmstadt, Germany).

\section{Preparation of standard solution}

Curcuminoids standard stock solution were prepared by appropriate amount of BDMC, DMC and CUR were dissolved with methanol in a $10 \mathrm{~mL}$ volumetric flask to obtain $500 \mu \mathrm{g} \cdot \mathrm{mL}^{-1}$ respectively. An appropriate amount of stock solution was mixed with methanol to obtain six concentration range from 0.5 to $50 \mu \mathrm{g} \cdot \mathrm{mL}^{-1}$.

\section{Preparation of sample solution}

C. xanthorrhiza was collected from Bogor West Java and Surabaya East Java, Indonesia. The sample was cut into small pieces, dried, pulverized into powder and sieved. C. xanthorrhiza powdered sample weighed accurately, then mixed with methanol and sonicated for $30 \mathrm{~min}$ at room temperature. The extracts were filtered with a $0.45 \mu \mathrm{m}$ membrane filter then diluted to $10 \mathrm{~mL}$ with methanol.

\section{Chromatographic conditions}

Chromatographic conditions for the separation of the three curcuminoids were performed on an LC-20A series HPLC with a diode array UV-Vis detector system (Shimadzu, Kyoto, Japan). Separation of the analytes was achieved on the Zorbax Eclipse Plus C18 column $(4.6 \mathrm{~mm} \times$ $150 \mathrm{~mm}, 5 \mu \mathrm{m})$. The mobile phase consisted of acetonitrile (A) and $0.001 \%$ formic acid (B) in water, with a flow rate was $1.0 \mathrm{~mL}$. $\mathrm{min}^{-1}$. The system of mobile phase applied was $0-20 \mathrm{~min}, 42-$ $58 \% \mathrm{~A}$. The column temperature for this study was kept at $30^{\circ} \mathrm{C}$, and the volume of the sample for separation was $20 \mu \mathrm{L}$. The curcuminoids detection wavelength was set at $425 \mathrm{~nm}$.

\section{Calculation of relative correction factors}

Determination of curcuminoids content in $C$. xanthorrhiza by QAMS was based on the comparison of each relative correction factor (RCF) to curcumin as an internal marker by following this equation (1):

$f_{x c}=\frac{f_{x}}{f_{c}}=\frac{A_{c} \times C_{x}}{A_{x} \times C_{c}}$

Where $f_{c}$ is the correction factor of curcumin (CUR) as internal marker, $f_{X}$ is the correction factor of analyte (BDMC and DMC), $A_{c}$ is the peak area of curcumin, $A_{x}$ is the peak area of analyte, $C_{X}$ is the concentration of analyte ( $\mu$ g.mL $\left.\mathrm{m}^{-1}\right)$ and $C_{c}$ is the concentration of curcumin $\left(\mu \mathrm{g} \cdot \mathrm{mL}^{-1}\right)$. The calculation of each $f$ values was done under different volumes of injection $(6,8,10,12,15$ and $20 \mu \mathrm{L})$.

\section{Calculation of relative retention time target compounds}

Determination of BDMC and DMC in $C$. xanthorrhiza by QAMS is only using one component as an internal marker i.e., CUR. Therefore, to determine the location of the peaks of the BDMC and DMC accurately, the ratio (2) or the difference of retention time must be determined.

$r_{x / s}=\frac{t_{R(x)}}{t_{R(c)}}$.............

Where $\mathrm{X}$ is analyte (BDMC and DMC), and $\mathrm{C}$ is marker (CUR). 


\section{Badrunanto}

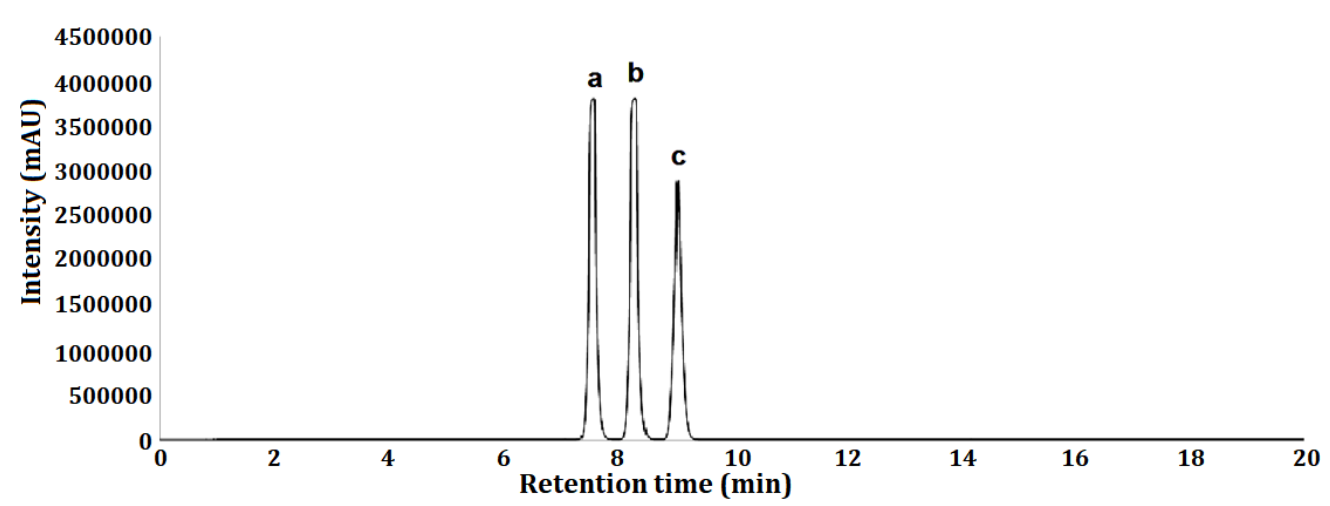

Figure 1 Chromatogram of standard of BDMC (a), DMC (b), and CUR (c).

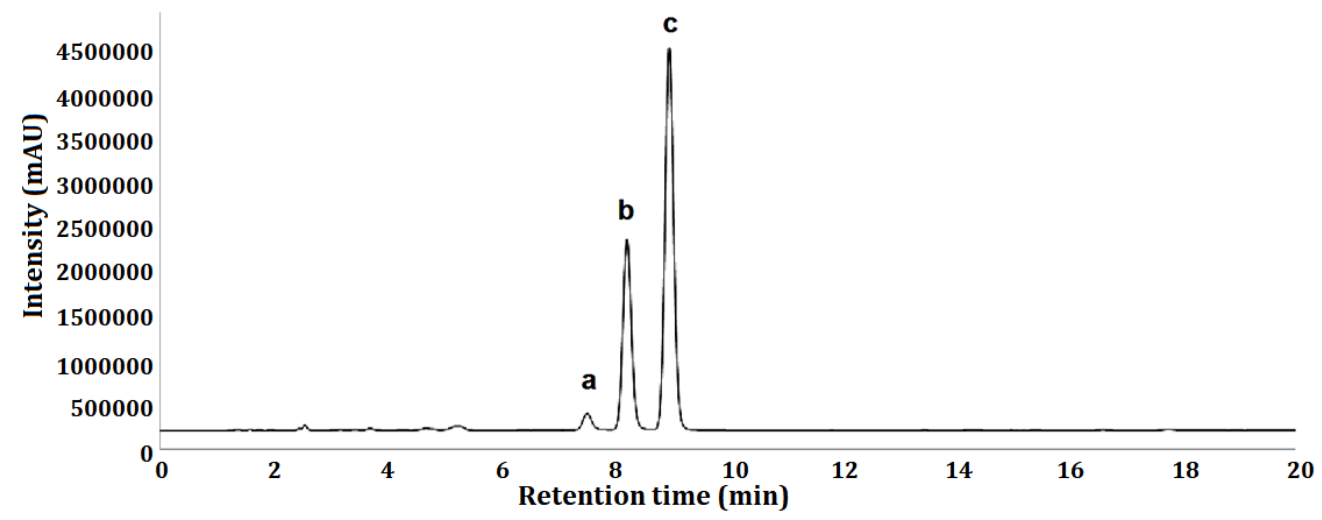

Figure 2 Chromatogram of BDMC (a), DMC (b), CUR (c) in sample of Curcuma xanthorrhiza.

\section{Method validation}

Validation of the method for determination of curcuminoids by QAMS based on Highperformance liquid chromatography was evaluated following the guideline from the Association of Official Analytical Chemists (AOAC). The system suitability, linearity, precision, accuracy, and stability were evaluated in this study.

\section{RESULT AND DISCUSSION \\ System suitability}

In order to develop a new quality control method to determine curcuminoids in $C$. xanthorrhiza based on chromatographic fingerprint, this study was combined with QAMS and HPLC fingerprint analysis. The chromatographic condition needs to evaluate to determine system suitability and has met the minimum standard requirements before it used for quantitative analysis. This evaluation was conducted by the optimization of mobile phase composition and column temperature. The resolution of each analyte was primarily used as the parameter for choosing the best chromatographic condition. The chromatograms of curcuminoids standard and sample, which has been optimized (Figures 1 and 2). The best separation was achieved when the column temperature was $30^{\circ} \mathrm{C}$, and the mobile phase was $42-58 \%$ acetonitrile in $0.001 \%$ formic acid in water for $0-20 \mathrm{~min}$. The resolution of each peak was $>1.5$ (acceptance criteria for resolution $>1.5$ ), and the total of analysis time for the quantitative analysis of curcuminoids was $37 \mathrm{~min}$. The detection wavelength for curcuminoids analysis was $425 \mathrm{~nm}$ because it gave the highest sensitivity.

\section{Linearity}

Calibration curves are used to determine the linearity of the method. The mixed standard (Figure 1) solution was diluted in series with methanol to obtain six different levels in the concentration range $0.5-10 \mu \mathrm{g} \cdot \mathrm{mL}^{-1}$ for BDMC and

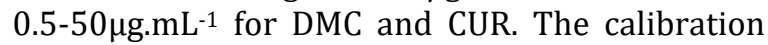
curve was plotted between the peak areas $(\mathrm{Y})$ against the concentration (X) of the analyte. 
Table I. Linearity of chromatographic method

\begin{tabular}{cccc}
\hline Analyte & Regression equation & $\left.\mathbf{( r}^{\mathbf{2}}\right)$ & Linear range $(\boldsymbol{\mu g} / \mathbf{m L})$ \\
\hline BDMC & $\mathrm{y}=251291 \mathrm{x}-13447$ & 0.9999 & $0.50-10.00$ \\
DMC & $\mathrm{y}=294272 \mathrm{x}-74885$ & 0.9999 & $0.50-50.00$ \\
CUR & $\mathrm{y}=202545 \mathrm{x}-37391$ & 0.9998 & $0.50-50.00$ \\
\hline
\end{tabular}

Table II. Sample stability, precision and recovery of chromatographic method

\begin{tabular}{|c|c|c|c|c|c|}
\hline \multirow{2}{*}{ Analyte } & \multirow{2}{*}{$\begin{array}{l}\text { Stability }^{\mathrm{a}} \\
\text { (RSD, \%) }\end{array}$} & \multicolumn{2}{|c|}{ Precision } & \multicolumn{2}{|c|}{ Recovery } \\
\hline & & Intra-day $^{\mathrm{b}}$ RSD (\%) & Inter-dayc RSD (\%) & Mean & RSD (\%) \\
\hline BDMC & 2.00 & 0.60 & 1.83 & 100.23 & 0.06 \\
\hline DMC & 2.14 & 2.66 & 1.65 & 103.95 & 0.15 \\
\hline CUR & 4.11 & 3.16 & 1.10 & 100.26 & 0.81 \\
\hline
\end{tabular}

a : Measurement at 0, 2, 4, 8, 12 \& 24 hrs after extraction; b: $n=6 ; c: n=3$.

Table III. Determination of RCF with curcumin as internal marker in C. xanthorrhiza

\begin{tabular}{ccccccccc}
\hline Injection volume $(\boldsymbol{\mu L})$ & $\mathbf{6} \boldsymbol{\mu} \mathbf{L}$ & $\mathbf{8} \boldsymbol{\mu L}$ & $\mathbf{1 0} \boldsymbol{\mu L}$ & $\mathbf{1 2} \boldsymbol{\mu L}$ & $\mathbf{1 5} \boldsymbol{\mu L}$ & $\mathbf{2 0} \boldsymbol{\mu L}$ & Mean & RSD (\%) \\
\hline$f_{B D M C}$ & 0.886 & 0.861 & 0.855 & 0.849 & 0.841 & 0.832 & 0.854 & 1.71 \\
$f_{D M C}$ & 0.715 & 0.709 & 0.707 & 0.703 & 0.701 & 0.697 & 0.706 & 0.58 \\
\hline
\end{tabular}

The correlation coefficients $\left(\mathrm{r}^{2}\right)$ of calibration curves for all analyte were $>0.9998$ (Table I). These high $\mathrm{r}^{2}$ values indicate that the method has good linearity and stable at wide range concentration. The acceptance criteria from AOAC for linearity $\left(r^{2}\right)$ is above 0.99 . So, the linearity result from our study have met the acceptance criteria of AOAC guidelines.

\section{Stability}

Stability was assessed by analyzing the solution of sample at $0,2,4,8,12$ and $24 \mathrm{~h}$ at room temperature after preparation of the sample. The result (Table II) showed that the RSD below 5\%, it means the analyte was stable after $24 \mathrm{~h}$ of extraction.

\section{Accuracy}

Recovery by the standard addition method was used to determine the accuracy of the method. The sample of $C$. xanthorrhiza was spiked by low, medium, and large amounts of three curcuminoids standards, and then these samples were extracted and analyzed for its recovery as described previously. Recovery of curcuminoids was in the range of $100.23-103.95 \%$ with the RSD was < 1\% (Table II). It showed that the recovery of this method was not statistically different and in accordance with the acceptance criteria of recovery is $80-120 \%$. So, the developed method was accurate.

\section{Precision}

The precision of this method was determined by intra-day and inter-day variations. Intra-day variation was assessed by six replications of the sample injection on the same day (Table II). Inter-day variation was assessed by injecting six replicates of samples on a different day. The RSD value is below $4.0 \%$ (acceptance criteria: RSD <4\%), indicating the method was precise.

\section{Quantitative analysis of multicomponent by single marker (QAMS)}

Curcumin was chosen as a marker for quantitative analysis of two other curcuminoids, i.e., DMC and BDMC, due to its highest pharmacological activity, easy to obtain, commercially available, and highest content in $C$. xanthorrhiza (Figure 2). To determine BDMC and DMC in QAMS, we used fxc. The RCF value of BDMC and DMC were determined by the variation of injection volume and then calculating used equation 1. The RCF of BDMC and DMC were 0.854 and 0.706 , respectively (Table III). These RCFs were stable in various injection volume, with RSD $1.71 \%$ and $0.58 \%$. These RCFs can be considered stable and can be applied in the QAMS method with a various injection volumes of sample extract. 
Table IV. RCFs stability by some chromatographic factors

\begin{tabular}{|c|c|c|c|c|}
\hline \multirow{2}{*}{ Chromatographic factors } & \multicolumn{2}{|c|}{ BDMC } & \multicolumn{2}{|c|}{ DMC } \\
\hline & RCF & RSD (\%) & RCF & RSD (\%) \\
\hline \multicolumn{5}{|l|}{ HPLC Column } \\
\hline Agilent, Zorbax C18 & 0.843 & \multirow{2}{*}{0.21} & 0.701 & \multirow{2}{*}{0.00} \\
\hline Shimadzu, Simpack ODS C18 & 0.840 & & 0.701 & \\
\hline \multicolumn{5}{|l|}{ Flow rate } \\
\hline $0.90 \mathrm{~mL} / \mathrm{min}$ & 0.841 & \multirow{3}{*}{0.59} & 0.700 & \multirow{3}{*}{0.21} \\
\hline $1.00 \mathrm{~mL} / \mathrm{min}$ & 0.843 & & 0.701 & \\
\hline $1.10 \mathrm{~mL} / \mathrm{min}$ & 0.852 & & 0.704 & \\
\hline \multicolumn{5}{|l|}{ Wavelength } \\
\hline $420 \mathrm{~nm}$ & 0.843 & \multirow{5}{*}{0.11} & 0.701 & \multirow{5}{*}{0.00} \\
\hline $423 \mathrm{~nm}$ & 0.843 & & 0.701 & \\
\hline $425 \mathrm{~nm}$ & 0.843 & & 0.701 & \\
\hline $427 \mathrm{~nm}$ & 0.842 & & 0.701 & \\
\hline $430 \mathrm{~nm}$ & 0.845 & & 0.701 & \\
\hline \multicolumn{5}{|l|}{ Column temperature } \\
\hline $27^{\circ} \mathrm{C}$ & 0.843 & \multirow{3}{*}{0.15} & 0.701 & \multirow{3}{*}{0.00} \\
\hline $30{ }^{\circ} \mathrm{C}$ & 0.841 & & 0.701 & \\
\hline $33^{\circ} \mathrm{C}$ & 0.840 & & 0.701 & \\
\hline
\end{tabular}

Table V. Determination of BDMC and DMC peak by retention time difference and retention time ratio

\begin{tabular}{|c|c|c|c|c|c|c|}
\hline \multirow{2}{*}{ Curcuminoids Standard $(\mu \mathrm{g} / \mathrm{mL})$} & \multicolumn{3}{|c|}{ BDMC } & \multicolumn{3}{|c|}{ DMC } \\
\hline & $t_{R}(\min )$ & $t_{R}$ & $\mathbf{t}_{\text {R.BDMC } / \mathbf{t}_{\text {R.CUR }}}$ & $t_{R}(\min )$ & $t_{R}$ & $\mathbf{t}_{\text {R.BDMC } / \mathbf{t}_{\text {R.CUR }}}$ \\
\hline 0.500 & 8.293 & 1.752 & 0.826 & 9.141 & 0.904 & 0.910 \\
\hline 1.000 & 8.217 & 1.768 & 0.823 & 9.073 & 0.911 & 0.909 \\
\hline 5.000 & 8.140 & 1.775 & 0.821 & 9.000 & 0.915 & 0.908 \\
\hline 10.000 & 8.194 & 1.771 & 0.822 & 9.053 & 0.912 & 0.908 \\
\hline 20.000 & 8.186 & 1.771 & 0.822 & 9.045 & 0.912 & 0.908 \\
\hline 50.000 & 8.213 & 1.767 & 0.823 & 9.070 & 0.910 & 0.909 \\
\hline Sample A & 7.700 & 1.599 & 0.828 & 8.473 & 0.826 & 0.911 \\
\hline Mean & & 1.767 & 0.823 & & 0.911 & 0.909 \\
\hline RSD (\%) & & 0.776 & 0.15 & & 0.35 & 0.07 \\
\hline
\end{tabular}

Stability test of RCFs in various chromatographic condition

The RCF stability is crucial for QAMS so that we could use this method in another column, instrument, or laboratories. The stability of BDMC and DMC were tested in a different column, column temperature, a flow rate of the mobile phase, and detection wavelength. Indicated excellent stability of RCFs under various conditions mentioned above (Table IV). The RSD values of all tests were $<1 \%$, so that we could use these RCFs for the simultaneous determination of BDMC and DMC along with CUR in C. xanthorrhiza.

\section{Determination of curcuminoids peak}

We will have difficulties determining BDMC and DMC by using only CUR as the reference marker in external standard method. However, in QAMS, we could locate each peak by CUR peak without the reference compound of BDMC and DMC. There are two methods in QAMS for determining the location of each peak. The first one calculates the differences of the retention time and the second one, the use of ratio between CUR and the other curcuminoids (BDMC and DMC). Table V showed that the ratio of retention time has better RSD than the differences in retention time for each target compound (BDMC 0.15\%; DMC 0.07\%).

\section{Comparison of QAMS and external standard method (ESM)}

In order to validate QAMS feasibility for simultaneous determination of curcuminoids determination in C. xanthorrhiza using curcumin as 
Table VI. Result comparison external Standard and QAMS for determination of Curcuminoids in $C$. xanthorrhiza

\begin{tabular}{|c|c|c|c|c|c|}
\hline \multirow{2}{*}{ Samples } & \multicolumn{2}{|c|}{ BDMC $(\mu \mathrm{g} / \mathrm{mL})$} & \multicolumn{2}{|c|}{ DMC $(\mu \mathrm{g} / \mathrm{mL})$} & \multirow{2}{*}{ CUR } \\
\hline & ESM & QAMS & ESM & QAMS & \\
\hline U1 & 1.03 & 1.04 & 10.48 & 10.55 & 33.52 \\
\hline $\mathrm{U} 2$ & 1.02 & 1.03 & 10.53 & 10.60 & 33.56 \\
\hline U3 & 1.03 & 1.04 & 10.54 & 10.61 & 33.57 \\
\hline U4 & 1.04 & 1.05 & 10.52 & 10.59 & 33.54 \\
\hline U5 & 1.04 & 1.05 & 10.48 & 10.55 & 33.54 \\
\hline U6 & 1.13 & 1.15 & 10.55 & 10.62 & 33.51 \\
\hline U7 & 1.04 & 1.05 & 10.52 & 10.59 & 33.61 \\
\hline U8 & 1.04 & 1.05 & 10.51 & 10.58 & 33.65 \\
\hline U9 & 1.04 & 1.05 & 10.52 & 10.59 & 33.54 \\
\hline U10 & 1.12 & 1.13 & 10.68 & 10.76 & 33.74 \\
\hline Mean & 1.05 & 1.06 & \multirow{2}{*}{\multicolumn{2}{|c|}{$\begin{array}{ll}10.54 & 0.65\end{array}$}} & 33.58 \\
\hline RE (\%) & \multicolumn{2}{|c|}{1.12} & & & \\
\hline T.BGR Local Market & 1.01 & 1.03 & 6.59 & 6.57 & 17.76 \\
\hline RE (\%) & \multicolumn{2}{|c|}{1.40} & \multicolumn{2}{|c|}{0.35} & \\
\hline T.sBY Local Market & 0.69 & 0.69 & 5.03 & 4.94 & 18.65 \\
\hline $\mathrm{RE}(\%)$ & \multicolumn{2}{|c|}{1.22} & \multicolumn{2}{|c|}{1.65} & \\
\hline
\end{tabular}

single marker, the contents of BDMC and DMC were determined by QAMS compared to ESM. Determination of BDMC and DMC, we used the following equation:

$C_{\mathrm{X}}=\left(\frac{\mathrm{A}_{\mathrm{x}} \mathrm{X} \mathrm{C}_{c}}{\mathrm{~A}_{c}}\right) f_{\mathrm{xc}}$

The relative error (RE) of the two methods calculated by determining the deviation and similarity of each results. In this study, we used $C$. xanthorrhiza rhizome samples from two locations (Bogor and Surabaya). Table VI showed no significant difference between QAMS and external standard method. The RE of BDMC and DMC in $C$. xanthorrhiza was $1.12 \%$ and $0.65 \%$, respectively, while BDMC and DMC from two local markets in Bogor and Surabaya were $<1.40 \%$ and $1.65 \%$ respectively. Based on this RE value, QAMS can be applied as the new alternative method for routine analysis and quality control of $C$. xanthorrhiza in the difference chromatographic condition. The use of curcumin as a marker to determine the other two curcuminoids has reduced the cost of quality control analysis and made QAMS more effective and efficient than ESM.

\section{CONCLUSION}

In this study, QAMS was proven could be used as an alternative method of routine analysis of curcuminoids in C. xanthorrhiza, which is efficient, precise, accurate, and reliable. The linearity of this method is $>0.9998$ for each component. In this method, curcumin is used as an internal standard to determine two other components (BDMC and DMC) based on each RCF values, which proven stable at the various chromatographic condition. The ratio of retention time was used to determine the location of two other components and proved stable.

\section{ACKNOWLEDGEMENT}

The authors would like to acknowledge the Directorate of Research and Community Service, Ministry of Research Technology and Higher Education of the Republic of Indonesia for financial support of this research by Penelitian Fundamental Grant 2019 (No: 4167/IT3.L1/PN/2019).

\section{REFERENCES}

Association of Official Analytical Chemists. 2002. Guidelines for Single Laboratory Validation of Chemical Methods for Dietary Supplements and Botanicals; AOAC: Rockville, MD. http://www.aoac.org/aoac_prod_imis/AOA C_Docs/StandardsDevelopment/SLV_Guidel ines_Dietary_Supplements.pdf (accessed Nov 18, 2018).

Chen Z, Zhao Y, Quan L, Zhou H, Cao D, Hu C, Li W, Yang Z. 2017. Study on Quality Standard of Processed Curcuma Longa Radix. Evidence- 
based Complementary and Alternative Medicine, 2017, 2830754. doi:10.1155/2017/2830754.

Devaraj S, Ismail S, Ramanathan S, Marimuthu S, Fei Y.M. 2010. Evaluation of the hepatoprotective activity of standardized ethanolic extract of Curcuma xanthorrhiza Roxb. Journal of Medicinal Plants Research, 4(23), $2512 \quad$ - 2517. doi:10.5897/JMPR10.453.

Erpina E, Rafi M, Darusman L.K, Vitasari A, Putra B.R, \& Rohaeti E. 2017. Simultaneous quantification of curcuminoids and xanthorrhizol in Curcuma xanthorrhiza by high-performance liquid chromatography. Journal of Liquid Chromatography and Related Technologies, 40(12), 635-639. doi:10.1080/10826076.2017.1343729.

Fadus M.C, Lau C, Bikhchandani J, Lynch H.T. 2017. Curcumin: An age-old anti-inflammatory and anti-neoplastic agent. Journal of Traditional and Complementary Medicine, 7(3), 339-346, National Taiwan University. doi:10.1016/j.jtcme.2016.08.002.

Jayaprakasha G.K, Jaganmohan Rao L, \& Sakariah K.K. 2006. Antioxidant activities of curcumin, demethoxycurcumin and bisdemethoxycurcumin. Food Chemistry, 98(4), 720-724. doi:10.1016/j.foodchem.2005.06.037.

Kim MB, Kim C, Song Y, Hwang J.K. 2014. Antihyperglycemic and Anti-Inflammatory Effects of Standardized Curcuma xanthorrhiza Roxb. Extract and Its Active Compound Xanthorrhizol in High-Fat DietInduced Obese Mice. Evidence-Based Complementary Alternative Medicine, 2014, 205915. doi: 10.1155/2014/205915.

Kocaadam B, \& Şanlier N. 2015. Curcumin, an Active Component of Turmeric (Curcuma longa), and Its Effects on Health. Critical Reviews in Food Science and Nutrition, 57(13), 2889289. doi:10.1080/10408398.2015.1077195.

Li F, Wu H, Sun L.L, Wu H, Wang R, Li S.P, Wang W, Dai L, Zhang Z, Fu J, Deng R. 2018. Quantitative analysis of multi-components by single marker and fingerprint analysis of Achyranthes bidentata blume. Journal of Chromatographic Science, 56(7), 595-603. doi: 10.1093/chromsci/bmy031.

Li R, Xiang C, Ye M, Li H.F, Zhang X, Guo D.A. 2011. Qualitative and quantitative analysis of curcuminoids in herbal medicines derived from Curcuma species. Food Chemistry, 126(4), 1890-1895. doi:10.1016/j.foodchem.2010.12.014.

Mangunwardoyo W, Deasywaty, Usia T. 2012. Antimicrobial and identification of active compound Curcuma xanthorrhiza Roxb. International Journal of Basic \& Applied Sciences - IJBAS-IJENS, 12(1), 69 - 78.

Moghadamtousi S.Z, Abdul Kadir H, Hassandarvish P, Tajik H, Abubakar S, Zandi K. 2014. A review on antibacterial, antiviral, and antifungal activity of curcumin. BioMed Research International. Hindawi Publishing Corporation. doi:10.1155/2014/186864.

Osorio-Tobón J.F, Carvalho P.I.N, Barbero G.F, Nogueira G.C, Rostagno M.A, \& Meireles M.A.D.A. 2016. Fast analysis of curcuminoids from turmeric (Curcuma longa L.) by highperformance liquid chromatography using a fused-core column. Food Chemistry, 200, 167 - 174. doi:10.1016/j.foodchem.2016.01.021.

Paramasivam M, Aktar Md.W, Poi R, Banerjee H, Bandyopadhyay A. 2008. Occurrence of curcuminoids in Curcuma longa: A quality standardization by HPTLC. Bangladesh Journal of Pharmacology, 3(2). doi:10.3329/bjp.v3i2.833.

Peng Y, Dong M, Zou J, Liu Z. 2018. Analysis of the HPLC Fingerprint and QAMS for Sanhuang Gypsum Soup. Journal of analytical methods in chemistry, 2018, 5890973. doi:10.1155/2018/5890973.

Rafi M, Wulansari L, Heryanto R, Darusman L.K, Lim L.W, Takeuchi T. 2015. Curcuminoid's Content and Fingerprint Analysis for Authentication and Discrimination of Curcuma xanthorrhiza from Curcuma longa by High-Performance Liquid Chromatography-Diode Array Detector. Food Analytical Methods, 8(9), 2185 - 2193. doi:10.1007/s12161-015-0110-1.

Rege S, Momin S, Wadekar S, Pratap A, Bhowmick D. 2014. Effect of demethoxycurcumin and bisdemethoxycurcumin on antioxidant activity of curcumin in refined sunflower oil. Journal of Food Processing and Preservation, 38(1), 296-303. doi:10.1111/j.17454549.2012.00777.x.

Sandur S.K, Pandey M.K, Sung B, Ahn K.S, Murakami A, Sethi G, Limtrakul P, Badmaev V, Aggarwal B.B. (2007). Curcumin, demethoxycurcumin, bisdemethoxycurcumin,

tetrahydrocurcumin and turmerones differentially regulate anti-inflammatory 
and anti-proliferative responses through a ROS-independent mechanism. Carcinogenesis, 28(8), 1765 - 1773. doi:10.1093/carcin/bgm123.

Wang L.L, Zhang Y.B, Sun X.Y, Chen S.Q. 2016. Simultaneous quantitative analysis of main components in linderae reflexae radix with one single marker. Journal of Liquid Chromatography and Related Technologies, 39(8), $422 \quad 427$. doi:10.1080/10826076.2016.1169429.

Wang Z.M, Gao H.M, Fu X.T, Wang W. H. 2006. Multicomponents quantitation by one marker new method for quality evaluation of
Chinese herbal medicine. Zhongguo Zhongyao Zazhi, 31(23), 1925-1928.

Xu R, Mao F, Zhao Y, Wang W, Fan L, Gao X, Zhao J, Tian H. 2017. UPLC Quantitative Analysis of Multi-Components by Single Marker and Quality Evaluation of Polygala tenuifolia Wild. Extracts. Molecules, 22(12), 2276. doi:10.3390/molecules22122276.

Zhu C, Li X, Zhang B, Lin Z. 2017. Quantitative analysis of multi-components by single marker - a rational method for the internal quality of Chinese herbal medicine. Integrative Medicine Research, 6(1), 1 - 11. doi:10.1016/j.imr.2017.01.008. 